\title{
Outros rumos na formação docente em artes visuais - Para onde caminhamos?*
}

\author{
Other ways on visual arts teachers' formation - Where are we heading to?
}

Otros cursos deformación delprofesoradoenartesvisuales-¿Hacia dóndenos dirigimos?

\author{
MARILDA OLIVEIRA DE OLIVEIRA** \\ THAIS RAQUEL DA SILVA PAZ****
}

\begin{abstract}
$\diamond$
RESUMO - Este artigo é resultado das análises realizadas no projeto "O que os alunos aprendem nas aulas de artes visuais no ensino médio". O foco da investigação foram as aulas ministradas pelos professores em formação inicial (estagiários do Curso de Licenciatura em Artes Visuais) a partir da tipologia de conteúdos proposta por Zabala (1998). Este projeto teve início em 2006 após uma longa pesquisa de campo (2006/2007 e 2008), buscando averiguar o contexto da educação das artes visuais nas escolas públicas de Santa Maria, onde foram entrevistados 56 professores com formação e atuação na área de artes visuais e 112 alunos de nível médio. Como continuação (2008 e 2009), foram propostas ações de formação continuada pelo Laboratório de Artes Visuais, CE/UFSM. Posteriormente (2009 e 2010), iniciamos um acompanhamento com os professores em formação inicial, escopo deste artigo, no qual foi possível perceber a importância dos diálogos construídos a partir da perspectiva da cultura visual no curso de Licenciatura em Artes Visuais da UFSM. Os estudos da cultura visual têm contribuído para novos posicionamentos dos professores no contexto escolar e formativo, possibilitando situações de vivências e colaboração entre professores e educandos.
\end{abstract}

Palavras-chave - Formação docente. Artes visuais. Cultura visual.

\begin{abstract}
This paper is the result of analyses done at the project "What students learn in high school's visual arts classes". The focus of this investigation were classes given by initial formation teachers (on training at Visual Arts Bachelor of Education) using a typology of contents which was proposed by Zabala (1998). This project was initiated after a long field research (2006/2007 and 2008) seeking to check the context of visual arts education at public schools of Santa Maria/RS, through interviews with 56 teachers with formation and experience on visual arts area, and with 112 high school students. We followed (2008 and 2009) with the proposition of continued formation actions by Visual Arts Laboratory, CE/UFSM. After that (2009 and 2010) we initiated an accompaniment with initial formation teachers, motif of this paper, and on which it was possible to perceive the importance of the dialogs which were constructed starting from the perspective of visual culture at UFSM's Visual Arts B.Ed. Visual culture studies have been contributing to new positions of the teachers at school and formative contexts, enabling situations of experience and collaboration between teachers and students.
\end{abstract}

Keywords - Teacher training. Visual arts. Visual culture.

RESUMEN - Este artículo es el resultado de los análisis realizados en el proyecto "Lo que los estudiantes aprenden en las clases de artes visuales en la escuela secundaria "El foco de la investigación fueron las clases impartidas por los profesores en formación inicial (pasantes Licenciatura en Artes Visuales), por el tipo de contenido propuesto por Zabala (1998). Este proyecto comenzó en 2006 después de una investigación de campo largo (2006/2007 y 2008), con objeto de averiguar el contexto de la educación de las artes visuales en las escuelas públicas de Santa María, donde se entrevistó a 56 profesores con formación y experiencia en el campo de las artes visuales y 112 estudiantes de la escuela. Como futuro (2008 y 2009), se propusieron acciones de educación continua por el Laboratorio de las Artes Visuales, CE/UFSM. Más tarde (2009 y 2010), se inició un seguimiento con los maestros en la formación inicial, el alcance de este artículo, en el que era posible darse cuenta de la importancia de los diálogos construidos desde la perspectiva de la cultura visual en la Licenciatura en Artes Visuales UFSM. Los estudios de la cultura visual han contribuido a los nuevos maestros en asignaciones a la escuela y el contexto de formación, lo que permite situaciones de experiencias y la colaboración entre profesores y estudiantes.

Palabras clave - Formación docente. Artes visuales. Cultura visual.

\footnotetext{
* Projeto de Pesquisa financiado pelo CNPq.

** Doutora em História da Arte pela Universidade de Barcelona (Barcelona, Espanha) e Professora da Universidade Federal de Santa Maria (Santa Maria, RS, Brasil). E-mail:<marildaoliveira27@gmail.com>.

*** Mestranda em Educação pela Federal de Santa Maria (Santa Maria, RS, Brasil). E-mail: <paz_thais@yahoo.com.br>.
} 


\section{PARA COMEÇAR ...}

As pessoas, as relações sociais, as concepções de poder, assim como a compreensão de sujeitos e de culturas, não só mudaram como também têm sido constantemente problematizadas e desterritorializadas, ${ }^{1}$ provocando novas práticas sociais e percepções sobre as realidades.

A comunicação na sociedade contemporânea está em contínuo processo de expansão, e as diferentes mídias que fazem parte dessa rede veiculam imagens de todas as ordens, a todo instante, atingindo diversos lugares e temporalidades. A televisão, a internet, as revistas eletrônicas, dentre outros meios, fazem circular imagens que acabam por fazer parte do nosso cotidiano e, tendo em vista este atual contexto, torna-se importante levarmos em conta que também aprendemos nas conexões que estabelecemos com esses meios. Passamos a compreender que essas relações fazem parte dos nossos processos de subjetivação ${ }^{2}$ e nos subjetivam enquanto pessoas, professores, estudantes, etc.

Assim, os processos de subjetivação pensados nesta pesquisa não têm relação com o sujeito e, de acordo com Deleuze (2007, p.123), "a subjetivação sequer tem a ver com a 'pessoa': é uma individuação, particular ou coletiva, que caracteriza um acontecimento (uma hora do dia, um rio, um vento, uma vida...). É um modo intensivo e não um sujeito pessoal". Isso significa compreendermos a relação entre os sujeitos e as imagens como possibilidade de acontecimento, de atribuição e produção de sentido.

As imagens sempre se fizeram presentes na escola e, principalmente, no contexto da educação das artes visuais; no entanto, ao levarmos em consideração que a subjetividade é produzida e que "esses processos de subjetivação são inteiramente variáveis, conforme as épocas, e se fazem segundo regras muito diferentes" (DELEUZE, 2007, p. 123), torna-se fundamental seguirmos problematizando nossas práticas neste contexto.

Nesse sentido, com essas mudanças temos procurado repensar o que significa ensino/aprendizagem e o que movimenta o desejo de ensinar/aprender nos cursos de Licenciatura em Artes Visuais neste momento. Assim como com o passar do tempo algumas roupas não nos servem mais, pois crescemos e nosso corpo se modifica, também mudamos nossos interesses, deixamos de realizar as mesmas práticas, de utilizar os mesmos referenciais teóricos e, principalmente, de satisfazer-nos com o que ensinamos e com o que aprendemos nos cursos de graduação.

Os cursos de licenciatura em artes visuais no nosso país têm produzido uma movimentação que merece ser considerada. No caso específico da nossa instituição, temos buscado levar em consideração a presença das imagens no cotidiano da sala de aula, estudando e procurando possibilidades para a inserção da mesma, de forma a vir ao encontro dessas diferentes relações que se estabelecem entre aquele que observa e aquele que é observado.

De acordo com Raimundo Martins (2009, p. 3719),

nas reflexões pós-estruturalistas, o princípio de heterogeneidade é o núcleo central que ambienta o conceito de interpretação dialógica. Essas reflexões têm seu foco no 'conceito de autor', nas 'teorias sobre o sujeito' e nas 'diversas identidades' que nos interpelam a partir de imagens, visualidades, narrativas e discursos de arte.

Dessa forma, as reflexões amparadas num posicionamento pós-estruturalista ${ }^{3}$ possibilitam deslocamentos nas formas como percebemos a imagem, questionando a concepção naturalizada de que esta esconde uma verdade a ser encontrada e decifrada. Passamos a compreender também que o mundo simbólico e suas formas são construções culturais, e a imagem desempenha importante papel nessas redes discursivas. De acordo com Duncum (2011, p. 20),

Dadas as novas circunstâncias em que vivemos, muitos arte-educadores têm defendido que o conteúdo da arte-educação deveria pautar-se pela cultura visual. Esse grupo abrange profissionais dos Estados Unidos (DUNCUM, 2002; FREEDMAN, 2003; TAVIN, 2003), da Europa (ILLERIS, 2008; VIDIELLA; HERNÁNDEZ, 2006), Ásia (PARK, 2006), África (LAUWRENS, 2005) e América Latina (DIAS, 2006).

Ainda que este amplo grupo de pesquisadores tenha especificidades nas suas concepções do que seja a cultura visual, eles concordam que este é um termo de origem híbrida reconhecido não como uma teoria, mas como um campo teórico que está sendo construído. Um reflexo das mudanças ocorridas "desde os anos 60 , por diferentes campos de conhecimento, envolvendo a história da arte, a linguística e a crítica literária, os estudos dos meios, estudos culturais e feministas" (MARTINS, 2009, p. 115). Um campo transdisciplinar, fundamentado pela teoria crítica, ${ }^{4}$ porém alinhado às abordagens pós-críticas, em que descreve uma situação onde obras de arte se fundem com referenciais de outras disciplinas e campos, como o da psicologia, da antropologia, da história, da filosofia, entre outros.

Quando falamos em educação das artes visuais a partir da perspectiva da cultura visual, não significamos apenas uma questão de ampliação dos artefatos visuais/ culturais levados ao contexto escolar, mas, principalmente, de reflexão sobre estratégias de como proporcionar 
experiências pedagógicas com diferentes visualidades e objetos. De acordo com Hernández (2011), falar a partir deste lugar é assumir um posicionamento epistemológico, metodológico e político, que compreende a história enquanto uma narrativa discursiva.

Nessa perspectiva, as visualidades são compreendidas como formas culturais de apresentar, narrar ou mencionar vivências, cotidianos e posicionamentos, caracterizando grupos de sujeitos, conceitos, valores e subjetividades. Sendo vistas, dessa forma, não mais como um espelho da realidade, mas como maneiras de mediar a construção de ideias. Nesse sentido, passa a ser fundamental pensar a aprendizagem em artes visuais como uma relação entre a construção da subjetividade individual e o contexto social, em que não existem mais receptores nem leitores, mas construtores e intérpretes, situando a nós e nossos educandos nas relações com o que vemos, nos questionando como, por que e que tipo de conexões construímos com essas visualidades. Ou seja, pensar em "como podemos produzir nossas próprias narrativas, imprimindo-lhes nossas digitais identitárias, sempre em transformação", (MARTINS, 2009, p. 116).

Os estudos da cultura visual possibilitam que na educação das artes visuais sejam exploradas experiências com a arte na qual possamos problematizar como somos subjetivados por diferentes imagens e artefatos, assim como o que produzimos durante esses processos. Esta perspectiva teórica nos proporciona a construção de uma narrativa na qual somos convidados a produzir, inventar. Isso não significa que apenas a discussão em torno da cultura visual seja capaz de tais logros no processo educativo em artes visuais, nem que desconheçamos ou silenciemos o acúmulo teórico, metodológico e epistemológico que a comunidade de pesquisadores brasileiros tem produzido na área ou mesmo nas diversas experiências bem-sucedidas em ensino de artes visuais que não usam necessariamente tal abordagem. Significa apenas que esta pesquisa adotou este posicionamento e foi a partir dele que este texto foi operacionalizado.

Ao experimentar outros posicionamentos na educação das artes visuais, e acreditamos que a cultura visual é um deles, possibilitamos que os educandos possam vislumbrar outras formas de se colocar e se relacionar em situações de sala de aula.

A própria produção artística contemporânea cada vez mais exige outras formas de relação e aproximação, pois ela não acontece mais somente na contemplação, observação atenta e solitária. De acordo com Cocchiarale (2006), contemplação é uma palavra que não cabe mais a produção artística produzida atualmente, pois ela acontece em um campo de tensões, em rede. E muitas vezes a arte se dá justamente com a participação do outro, de forma colaborativa e, ainda, com propostas nas quais se perde o "autor" da produção. O artista Alexandre Órion (Figura 1 - imagem trabalhada por uma das professoras que participou deste estudo, realizado em 2009 e 2010, quando acompanhamos os professores em formação inicial), por exemplo, deixa de ver a cidade apenas como suporte para o grafite, e passa a problematizá-la em seu trabalho enquanto um espaço público no qual inúmeras relações acontecem.

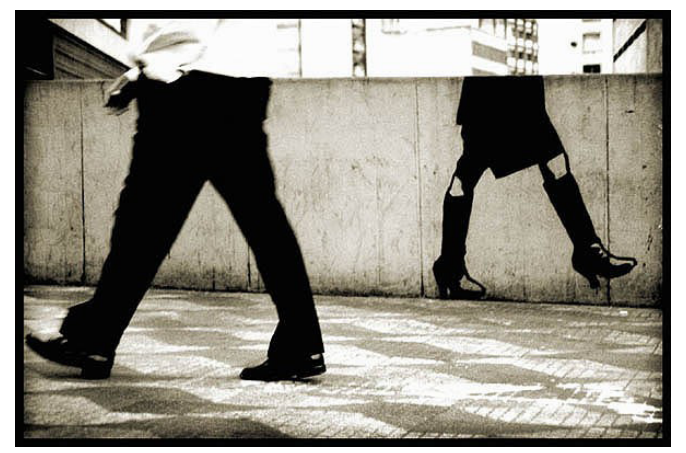

Figura 1 - Alexandre Órion. Metabiótica 5, 2003. Intervenção urbana seguida de registro fotográfico.

Fonte: $<$ http://www.alexandreorion.com/meta/>. Imagem utilizada no planejamento de aula de Tamiris Vaz (colaboradora da pesquisa).

Órion planeja o trabalho, realiza o grafite e, no entanto, sua produção só acontece quando alguém interage com o grafite produzido por ele nos muros da cidade. Ele espera até que as pessoas que passam pelo local se tornem de alguma forma parte desse processo, e através da fotografia registra o momento em que as pessoas se relacionam com o grafite produzido por ele. Neste tipo de produção artística, o acaso e o imprevisto se fazem presentes, e os transeuntes da cidade, quando se tornam coautores do trabalho, criam possibilidades, acrescentam coisas que o artista jamais poderia imaginar.

Produções artísticas como essa, quando pensadas no contexto da educação, podem nos provocar alguns questionamentos como: Quanto compreendemos a escola e a educação enquanto espaços nos quais diferentes relações acontecem e inúmeras conexões são produzidas dentro e fora deste contexto? O educando não é também parte dessa produção? Assim como o artista Alexandre Órion, nos preocupamos em planejar, organizar uma aula na qual haja espaço também para o acaso, para o imprevisto? Compreendemos os educandos como coautores do processo educativo?

A produção artística contemporânea tem desafiado as classificações habituais de arte, pois ela acontece na articulação de diferentes linguagens, nas relações com o cotidiano, no uso de tecnologias, na provocação de outros posicionamentos no público, assim como também problematiza o mercado e o sistema de legitimação. Dessa 
forma, temos procurado refletir sobre como poderíamos desafiar os sentidos naturalizados de que a educação acontece na transmissão de verdades a serem reproduzidas, na transformação dos sujeitos através da educação, no contexto da sala de aula, com conteúdos mais importantes que outros, na busca por respostas corretas, etc., e assim experimentar outros posicionamentos neste contexto.

No nosso curso de Licenciatura em Artes Visuais temos busca do propor uma articulação curricular que não seja viabilizada apenas na superfície, mas acerca do imbricamento das ementas e disciplinas. Dessa forma, o que este estudo pretende é averiguar até que ponto nossos profissionais estão em consonância com estas urgências.

A metodologia utilizada neste estudo foi de caráter qualitativo, no sentido de acompanhar e vivenciar as atividades desenvolvidas pelos professores em formação inicial, estagiários de artes visuais. Como instrumentos para o levantamento dos dados, entre os professores e seus educandos, fizemos uso da entrevista semi estruturada, abordando inicialmente questões como: o que os educandos aprendem nas aulas de artes visuais, que tipos de conteúdos são trabalhados nestas aulas e qual a relevância dos conteúdos trabalhados para suas vidas. Utilizamos também o diário de campo, assim como a análise documental dos planejamentos dos professores, dos registros gráficos e visuais das aulas e da produção artística dos educandos. As análises foram feitas a partir da tipologia de conteúdos proposta por Zabala (1998) no intuito de perceber como os professores em formação inicial articulam esses conteúdos em seus planejamentos e em suas aulas e também a partir dos referenciais de Meyer e Paraíso (2012).

Temos compreendido os estudos da cultura visual, durante a formação inicial, enquanto campo teórico que pode colaborar no processo de reinvenção da docência em artes visuais. Buscamos caminhar de forma a nos entregar a esta trilha, um trajeto que existe e abre caminho para novos olhares, sem levar a um lugar predeterminado. Um caminhar do qual nos fala Masschelein (2008, p. 39):

[...] um tipo de prática de pesquisa que envolve estar atento, que é aberta para o mundo, exposta (ao texto) para que ele possa se apresentar a nós de forma que nos comande. Esse comando não é o poder de um tribunal, não é a imposição de uma lei ou princípio (que supostamente deveríamos reconhecer ou impor a nós mesmos), mas sim a manifestação (aprendizado) de uma força que nos põe em movimento e assim abre o caminho. Ela não nos direciona, não nos leva à terra prometida, mas nos impulsiona. Ela não nos diz aonde ir, mas impulsiona para que nos desloquemos de onde (quem) estamos (somos).

Com isso, queremos dizer que o que está em jogo não é o julgamento, não é avaliar o presente projetando o futuro, mas que esta é a trilha que neste momento nos dedicamos a percorrer, a nos entregar. Temos procurado estar atentos a este presente que nos atravessa e contamina, para que as experiências sejam possíveis na formação docente em artes visuais.

\section{FORMAÇÃO INICIAL EM ARTES VISUAIS}

A palavra docência tem suas raízes no latim, docere, que significa ensinar, instruir, mostrar, dar a entender. Arte também vem do latim, ars, e quer dizer articular, ação de construir, juntar as partes. Nesse sentido, docência em arte seria o ato de ensinar a articular, mostrar como construir, dar a entender como amarrar duas partes (OLIVEIRA, 2008).

Essa é a base de nossas reflexões sobre a prática docente. Procurar encontrar maneiras para construirmos uma prática na qual sejamos capazes de articular ideias e pensamentos, de descobrir juntos como construir caminhos possíveis, compreender como amarrar conhecimentos específicos e pedagógicos de forma a nos auxiliar na proposição de uma nova configuração de ensino da arte.

A docência em arte possui uma trajetória construída historicamente, atravessando diferentes períodos, momentos teóricos e contextos sociopolíticos diversos.

No caso específico da formação profissional de professores de Artes Visuais da UFSM temos uma trajetória de licenciatura de trinta e três anos. Considerando as finalidades no ensino desse campo do conhecimento e, ainda, o papel e o modelo de professor que se busca e se quer, o lugar dado à educação no desenvolvimento humano, bem como, no caso específico, às construções do conhecimento em Arte são alguns dos fatores que nos levaram a elaborar uma nova proposta de Curso de Licenciatura para um curso de formação de professores para o ensino das Artes Visuais, ou seja, Curso de Licenciatura Plena em Artes Visuais (OLIVEIRA, 2008, p. 1).

Da mesma forma pontua Baptaglin (2010, p. 31): “[...] com a implantação da reforma curricular de 2004, as disciplinas pedagógicas passam a ser ministradas a partir do primeiro semestre do curso, o que propicia uma aproximação bem mais cedo ao campo de trabalho onde este profissional irá atuar". Enquanto curso de Licenciatura em Artes Visuais da UFSM, através dessa reforma curricular, tínhamos como principal intenção organizar um curso de formação de professores que constituísse situações de ensino e pesquisa, pensado com base na ideia de um professor que provoque experiências e institua diálogos renovadores com sua prática. Um docente em arte capaz de ensinar a articular, de construir caminhos de possibilidades, de invenção de problemas. ${ }^{5}$ 
Para Kastrup (2001), inventar problemas é propor experiências de problematização, é causar um estranhamento capaz de nos forçar a pensar, a aprender e construir outras formas de lidar com que já conhecemos e fazemos. É uma política pedagógica que prioriza os agenciamentos, que consiste numa relação de experimentar e compartilhar problematizações e, por isso, não possui resultado garantido.

Passamos a demarcar também o importante papel do estágio curricular no curso. E, ao pensar a formação inicial em artes visuais a partir da perspectiva da cultura visual, temos procurado fazer do estágio curricular um lugar de criação de situações de vivências. Um momento no qual o processo formativo aconteça através do diálogo entre os conhecimentos específicos e pedagógicos com o espaço e com o grupo que já vive nesse território.

Para isso, Oliveira (2009) propõe pensar a formação inicial a partir de cinco eixos: ideia de rede - cartografia; conteúdos culturais subjetivados; leitura para a transformação; prática educativa coletiva; e ambiência clima favorável.

O primeiro, procura pensar a formação inicial a partir da ideia de rede, da interdependência, da coletividade, de forma a ser definida por suas conexões, por pontos de diálogos e afastamentos, de territórios a ser transitados, deslocados. O segundo propõe pensar os conteúdos culturais subjetivados, as teorias e as leituras que realizamos de forma a subjetivar e ser subjetivadas por nossas práticas, nossas vivências no contexto escolar e formativo. $\mathrm{O}$ terceiro nos convida a perceber a leitura enquanto um processo de compreensão, de interação e de formação, no qual nutrimos nossas práticas. O quarto faz referência à prática educativa coletiva, ao convívio, ao compartilhamento com pares e grupos diversos que realizamos durante esse processo. E, por último, o eixo que diz respeito à ambiência, ao espaço prazeroso, ao clima favorável ao trabalho que é construído através do respeito, do diálogo e apoio colaborativo.

Compreender o processo formativo enquanto um lugar propício à experiências, à invenção, a deixar-se levar e sentir-se tocado por aquilo que lemos, escrevemos, conhecemos e vivenciamos. Promover espaços de criação, de forma a tirar o que existe de evidente, evitando o senso comum e o reducionismo. Um lugar no qual possamos discutir, confrontar, duvidar, construir e transformar o que lemos e produzimos, assim como socializar/compartilhar as experiências que temos durante esse processo.

A cultura visual, nesse sentido, tem sido o caminho adotado por nós, mas novamente é importante que se diga que não é o único nem o melhor, apenas mais um. Esta escolha tem nos possibilitado novos percursos e brechas para conviver com questões já instituídas no campo da educação e da arte, assim como nos provocado a revê-las, questioná-las e pensá-las de outras formas (OLIVEIRA, 2011).

Essa perspectiva teórica abre espaços para que nos tornemos autores do processo formativo ao interpretar as leituras, assim como dar sentido às práticas e às relações estabelecidas. Ao compreender a formação enquanto processo nunca acabado, sempre possível de outros sentidos e interpretações, tornamos possíveis outras posturas de investigação, de professor, de educação.

"A cultura visual não é partícipe dos exclusivismos e unilateralidades, ao contrário, alimenta-se da dispersão, dialoga com várias perspectivas teóricas e metodológicas já que nasceu híbrida" (OLIVEIRA, 2011, p. 187). E, nesse sentido, ao invés de encontrarmos território firme, continuamos a transitar por lugares de possibilidades, de incertezas e questionamentos que nos convidam a pensar em estratégias que facilitem experiências de relação pedagógica e maneiras de aprender.

Somos seres humanos em processo e, portanto, professores também em processo. Dessa forma, não podemos pensar a educação e a formação docente enquanto algo que é, mas que está sendo, e por isso aberta a modificações, rearticulações e adaptações.

\section{CAMINHAR É EXPOR-SE, COLOCAR-SE EM RISCO...}

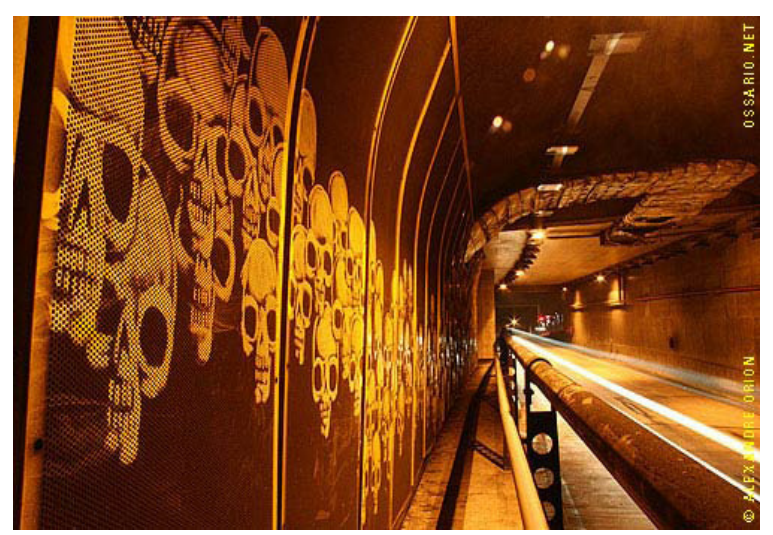

Figura 2 - Alexandre Órion. Ossário, 2006. Intervenção urbana.

Fonte: $<w w w$.alexandreorion.com $>$. Imagem utilizada no planejamento de aula de Tamiris Vaz (professora em formação inicial).

Eu estou trabalhando a arte com ênfase na arte pública, [conforme Fig. 2], relacionando o espaço público da escola. Como ele, o educando, se relaciona com esses espaços, vendo que tipo de artistas trabalha também com essas questões do cotidiano, com temas e espaço cotidiano. Questão do público e do privado, tanto o que é arte pública e o que poderia ser considerado uma arte então menos pública, mas também quais são os espaços que eles consideram públicos e privados dentro dos lugares onde eles se relacionam. ${ }^{6}$ 
De que forma este tipo de proposta se diferencia de proposições anteriores no campo da educação das artes visuais? Como seria ensinar e aprender a partir da cultura visual? O que significa discutir a arte em espaços públicos e privados? E que discursos são produzidos a partir dos sentidos dados pelos educandos ao expandir a discussão dos conceitos de público e privado para o contexto da escola, da cidade, da família, da internet? Quais os caminhos que a formação inicial em artes visuais tem procurado percorrer? Esses questionamentos têm a pretensão de apresentar o caminho percorrido no planejamento de aula realizado por esta professora, colaboradora da pesquisa, sem com isso pretender qualquer ideia de avanço ou retrocesso, apenas marcar o percurso.

Em 2009 e 2010, como já mencionado, acompanhamos um grupo de professores em formação inicial em artes visuais e seus planejamentos didáticos, foco deste artigo. A partir de quatro questões - o que ensinar, a quem e por que, e qual a relevância destes conteúdos para a vida dos educandos - analisamos os planejamentos e seus conteúdos a partir da tipologia proposta por Zabala (1998), na qual o autor classifica os conteúdos trabalhados na escola em uma escala de quatro tipos. Segundo ele, temos os conteúdos factuais, que são aqueles relativos a fatos que aconteceram em determinado período; conteúdos de conceitos e princípios, que são os abstratos, aqueles que exigem a nossa compreensão; conteúdos procedimentais são aqueles que funcionam como um conjunto de ações ordenadas para atingir um objetivo, como ler, desenhar, observar, classificar, analisar; e, como conteúdo atitudinal, aqueles relativos a valores, atitudes, comportamentos, padrões ou regras, que supõem o reflexo de imagens, de símbolos ou experiências promovidas a partir de modelos de um grupo.

A partir das entrevistas realizadas com os professores em formação inicial e os educandos foi possível perceber a presença de conteúdos factuais e procedimentais, mas também a presença dos conteúdos de conceitos $e$ princípios e atitudinais de forma articulada nos planejamentos e aulas.

Eu tenho trabalhado com história da arte, com diferentes mídias, técnicas de escultura e materiais que podem ser usados. Trabalhei com as diferenças do artesanato, assim como com a questão do tridimensional nos trabalhos com comparativo com os bidimensionais, como colagem, desenho. Propus também a produção de textos, produção escrita, pois eles tinham vergonha de falar. Solicitei que eles escrevessem sobre o trabalho para tentar refletir em cima do que eles faziam. No meu projeto, a ideia de trabalhar com o tridimensional seria para eles conhecerem melhor o espaço e saber que eles podem interagir nele. Não só o espaço que o corpo deles ocupa, mas eles trabalharem alguma coisa nesse espaço. No espaço deles, da sala de aula, da escola. Buscar isso, que eles possam compreender o espaço. ${ }^{7}$
É importante compreendermos que não se trata de negar o que já foi feito no campo da educação das artes visuais, mas de ampliarmos a maneira como trabalhamos esses mesmos conteúdos e imagens, refletindo e discutindo as práticas realizadas e os resultados obtidos. Isso significa que os professores em formação inicial trabalham em seus planejamentos movimentos, técnicas, períodos e linguagens artísticas, assim como com a produção realizada pelos educandos, que, segundo Zabala (1998), trata-se de conteúdos factuais e procedimentais. O que diferencia são as formas, as abordagens utilizadas pelos professores para trabalhar com esses conteúdos.

É importante que os educandos experimentem as linguagens das artes visuais, conheçam a história da arte, mas também é de grande relevância que se problematize com eles quais os sentidos dados ao que produzem, conhecem e ao que visualizam no contexto de sala de aula e no dia a dia. De acordo com Hernández (2011), este posicionamento significa considerar as práticas artísticas como práticas discursivas que têm efeitos nas maneiras de ver e de ver-se.

Eu tento fazer com que eles aprendam mais sobre si do que sobre a arte, por que não adianta eles estarem conhecendo os artistas, entender os trabalhos dos artistas, se eles não sabem que relação isso tem com a vida deles. É perceber que tu não estás conduzindo apenas para si, mas que isso vai ter uma implicação no espaço em que se está produzindo, com as pessoas que tu estáste relacionando. ${ }^{8}$

Esse posicionamento por parte dos professores, que compreende as relações e conexões estabelecidas entre o sujeito e os objetos, entre o sujeito e as visualidades, entre o sujeito e outro, contribui para que as artes visuais deixem de ser apenas mais uma disciplina no currículo escolar ao oferecer propostas a partir das quais os estudantes possam aprender sobre si mesmos, os outros e o mundo em que vivem.

Os professores preocupam-se em encontrar estratégias para relacionar estes conteúdos específicos das artes visuais ao contexto dos educandos, procurando, a partir da arte, tratar ainda de questões que incluem o cotidiano, abrindo espaço para que os conteúdos de conceitos $e$ princípios e atitudinais se façam presentes nessas aulas.

A professora em formação inicial, no momento da pesquisa, tinha como temática principal a arte pública, mas ela menciona a necessidade de trazer outros momentos artísticos e diferentes linguagens para aproximar os educandos das questões referentes à arte e a relação com o espaço público, assim como exemplos e situações do cotidiano.

A arte pública ${ }^{9}$ pode ser facilmente compreendida enquanto uma arte realizada fora dos museus e galerias. 
No entanto, se pensarmos a arte pública dentro da tendência da produção contemporânea, ela é entendida enquanto uma arte que se volta para o espaço onde é produzida, inserida, exposta. Uma produção artística na qual o espectador deixa de ser apenas um observador distante ao tornar-se parte do trabalho.

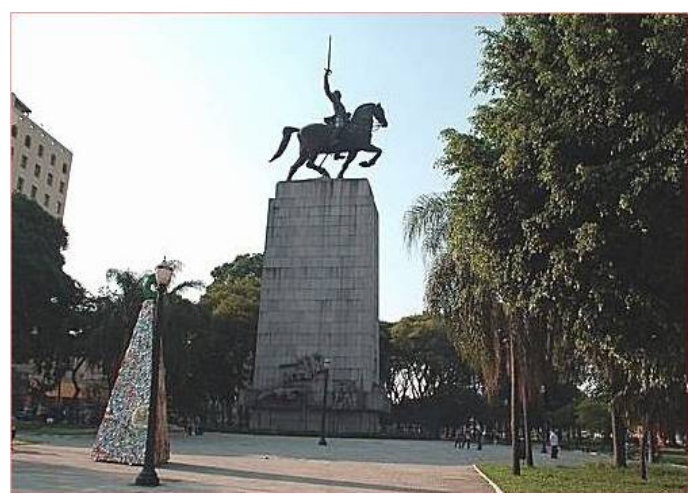

Figura 3 - Vitor Brecheret.

Monumento a Duque de Caxias, São Paulo.

Escultura (Peça: Bronze 15,88m × 4,10m × 13,20/Pedestal: Granito $22,28 \mathrm{~m} \times 6,70 \mathrm{~m} \times 11,51 \mathrm{~m})$.

Fonte: $<$ http://www.monumentos.art.br/monumento/duque_de_caxias $>$. Imagem utilizada no planejamento de aula de Sara Huppes (colaboradora da pesquisa).

Os monumentos nas ruas e praças (como exemplificado na Fig. 3) podem ser considerados arte pública por estarem em um local de livre acesso e, no entanto, ser tão intocáveis quanto produções que estão fechadas em galerias e museus. Mas, se pensarmos a partir da cultura visual, é possível construir uma ponte entre esses monumentos e as experiências dos estudantes, já que ela se dá na mediação, na articulação dessas produções com suas vivências, na possibilidade de que os educandos produzam suas próprias narrativas.

É importante tratar estas questões, construir com os educandos uma discussão sobre as diferentes concepções e entendimentos, assim como trazer para o contexto de sala de aula os movimentos e períodos artísticos que vão dando forma para o que entendemos hoje como arte pública, e que amanhã ou depois pode adquirir outros sentidos.

São problematizações que apresentam grande potencial quando trazidas para o contexto da escola e dos estudantes. Como nos relacionamos com a arte? Por que ela está ali? O que ela tem a ver com o contexto? O que faz com que determinado artefato seja arte? O que faz com que um objeto artístico seja considerado público ou privado? Essas são questões que, por exemplo, podem ser produzidas independentemente das imagens ou objetos com os quais trabalhamos no contexto de sala de aula.
De acordo com os educandos participantes da pesquisa, o que existe de mais relevante nos conteúdos trabalhados pelos professores em formação inicial é justamente a (re)construção dos modos de ver as aulas de artes, ampliando conceitos, ideias e concepções do que é a arte, e de como ela pode se relacionar com o cotidiano de cada um. Dessa forma, a educação das artes visuais deixa de ser vista apenas como "só papel e caneta, e tu fazer o que o professor te pede". ${ }^{10}$

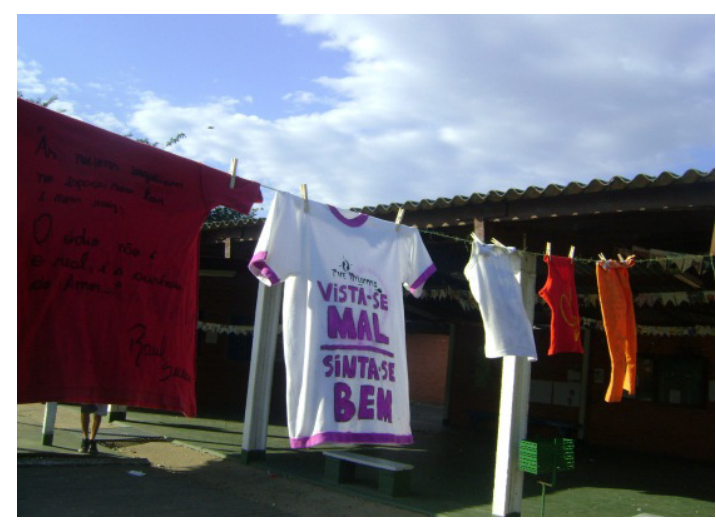

Figura 4 - Trabalho realizado pelos estudantes, 2010. Fonte: Diário visual de Tamiris Vaz, professora em formação inicial (colaboradora da pesquisa).

A educação das artes visuais a partir da cultura visual possibilita que partindo dos conteúdos de arte se discuta sobre o que nos preocupa cotidianamente. É construir opinião sobre assuntos de interesse, inventar nossas próprias narrativas sobre determinada situação, imagem ou objeto, discutir em grupo e construir trabalhos colaborativos que também vão estar em relação com as pessoas que estão nesses espaços, tornando-se "não só uma coisinha, assim, que ninguém vai dar bola, que tu vai só ganhar ponto com o professor [sic]. É uma coisa até mais prazerosa de tu fazer". ${ }^{11}$ Os estudantes percebem que não estão fazendo trabalhos que são somente para o professor avaliar, mas para um grupo maior que pode ser a comunidade da escola, estudantes de outras turmas e turnos que também vão visualizar e interagir com suas produções artísticas.

Discussões e propostas que acontecem a partir do aprofundamento de conteúdos específicos das artes visuais também foram muito mencionadas e valorizadas pelos educandos: "Primeiro a gente tenta aprender mais sobre aquilo, como que a gente pode trabalhar, o que significa aquilo que a gente quer fazer, e qual é a ideia que a gente quer desenvolver. A gente para, pensa, organiza, e depois faz o projeto". ${ }^{12}$ Ao aprofundar uma questão específica do campo da arte e redimensioná-la para outros contextos, o professor possibilita aos estudantes refletir e problematizar 
o que eles desejam abordar em seus trabalhos, assim como escolher técnicas, materiais, linguagens artísticas e locais que são mais apropriados para os sentidos que eles desejam dar para essas produções.

Percebemos que os professores em formação inicial procuram criar espaços nos quais os educandos possam buscara relação entre os artistas que estão conhecendo, o trabalho que estão realizando e as descobertas de si, assim como as relações que eles têm com esses espaços e com as pessoas que interagem com eles.

Eu acho que eles ficam mais curiosos. Que nem quando eu trabalhei com o tridimensional, eles ficavam mais curiosos para ver as coisas, esculturas. Eles foram à praça ver os bustos. Eles vêm discutindo sobre questão de materiais, esse tipo de coisas. ${ }^{13}$

Os planejamentos realizados pelos professores em formação inicial, ao levar em consideração a relação estabelecida entre os conteúdos específicos das artes visuais e as interpretações e produções dos educandos, proporcionam a aprendizagem dos conteúdos atitudinais, que, de acordo com Zabala (1998, p. 48):

[...] supõe um conhecimento e uma reflexão sobre os possíveis modelos, uma análise e uma avaliação das normas, uma apropriação e elaboração do conteúdo, que implica a análise dos fatores positivos e negativos, uma tomada de posição, um envolvimento afetivo e uma revisão e avaliação da própria atuação.

A presença dos conteúdos propostos por Zabala (1998) de forma interligada nos planejamentos demonstra a preocupação por parte dos professores em formação inicial em relacionar a arte com o cotidiano dos educandos, proporcionando espaços nos quais eles produzam suas próprias narrativas a partir de experiências em artes visuais.

Dessa forma, temos percebido a importância dos diálogos construídos sobre a arte contemporânea e os estudos da cultura visual durante a formação inicial, pois as experiências durante o processo subsidiam a construção dos planejamentos, de forma que os professores passem a priorizar relações nas quais os conteúdos trabalhados nas aulas de artes visuais tenham relevância para a vida dos educandos.

\section{O QUE HÁ LÁ PARA SE VER E OUVIR? ${ }^{14}$}

Como a urgência em tratar as aulas de artes visuais na educação básica como uma disciplina que de fato seja significativa para a vida dos educandos, está sendo abordada pelo professor de artes visuais? Como os educandos estão percebendo a arte na escola?
$\mathrm{Na}$ fase conclusiva da pesquisa, procuramos perceber como o professor em formação inicial procura diminuir o distanciamento entre o que se ensina nas aulas de artes visuais na escola e o que os adolescentes vivem e aprendem fora dela, facilitando assim as formas de ver, sentir e se relacionar com a arte.

Compreendemos que a presença da arte contemporânea na escola aproxima o educando, que deixa de ver a arte como uma produção impossível de ser realizada por alguém que não possua "o dom" ou como uma produção hierarquizada. A arte contemporânea nos convida a experimentar recombinações, imprevistos, assim como nos ajuda a compreender que o valor artístico não está no objeto, mas nas relações de poder que conformam esse objeto enquanto arte.

A cultura visual compreende as visualidades como um vir a ser nunca realizado, mas que deseja cumprirse no encontro. É nas conexões estabelecidas que os sentidos vão sendo dados, produzidos. De acordo com os educandos, conhecer "artistas vivos", dialogar sobre as relações entre a arte e o contexto, trabalhar em grupo, discutir em coletivo sobre a proposta que irão realizar, assim como explorar outros materiais, suportes e espaços proporciona outras experiências com a arte e o lugar no qual se relacionam. Estes poderiam ser alguns dos outros rumos na formação docente em artes visuais por onde podemos caminhar, título dado a este artigo.

Neste momento, acreditamos que os estudos teóricos referentes ao campo da cultura visual, a partir da provisionalidade, ${ }^{15}$ contribuem com as práticas educativas em sala de aula e possibilitam "incorporar a problemática que esteve fora da esfera da arte na educação"(HERNÁNDEZ, 2011, p. 43), a partir de problematizações do que seja originalidade, autoria, representação, intenção do artista, expressão, coletivo, etc., explorando situações e experiências nas quais os educandos possam ser capazes de compreender, elaborar suas próprias narrativas, investigar as relações entre a construção cultural e a arte, refletir sobre o percurso e encontrar o seu lugar de aprendizagem com sentido.

Decidimos deixar o conforto de formas já instituídas na educação e saímos em busca de outras vivências. Uma caminhada que não tem um destino ideal, em que não há conforto, mas na qual a formação docente em artes visuais necessita entregar-se, pois só caminhando tornaremos possível a experiência. Experiência na qual a educação das artes visuais procure proporcionar aos estudantes da educação básica um espaço de articulação entre o que aprenderam e de como estes conhecimentos possam auxiliá-los além do que se refere à interpretação do mundo, mas em relação ao seu posicionamento nele. 


\section{REFERÊNCIAS}

ARTE PÚBLICA. Itaú Cultural. Disponível em: <http:// www.itaucultural.org.br/aplicexternas/enciclopedia_ic/index. $\mathrm{cfm}$ ? fuseaction $=$ termos_texto\&cd_verbete $=356>$. Acesso em: 26 nov. 2011.

BAPTAGLIN, Leila Adriana. Construindo projetos, arquitetando ideias, analisando dados: a reforma curricular do curso de licenciatura em artes visuais-2004/UFSM. 112f. Dissertação (Mestrado em Educação) - Universidade Federal de Santa Maria, Santa Maria, 2010. 112 p.

COCCHIARALE, Fernando. Quem tem medo da arte contemporânea? Recife: Fundação Joaquim Nabuco, Editora Massangana, 2006.

DELEUZE, Gilles. O abecedário de Gilles Deleuze. Realização de Pierre-André Boutang, produzido pelas Éditions Montparnasse, Paris. No Brasil, foi divulgado pela TV Escola, Ministério da Educação. Tradução e Legendas: Raccord [com modificações]. A série de entrevistas, feita por Claire Parnet, foi filmada nos anos 1988-1989.

Conversações. São Paulo: Editora 34, 2007.

DUNCUM, Paul. Por que a arte-educação precisa mudar e o que podemos fazer. In: MARTINS, Raimundo; TOURINHO, Irene (Org.). Educação da cultura visual: conceitos e contextos. Santa Maria: Ed. da UFSM, 2011. p. 15-30.

GUATTARI, Félix. Caosmose: um novo paradigma estético. Tradução Ana Lúcia de Oliveira e Lúcia Cláudia Leão. São Paulo: Ed. 34, 1992.

HERNÁNDEZ, Fernando. A cultura visual como um convite à deslocalização do olhar e ao reposicionamento do sujeito. In: MARTINS, Raimundo; TOURINHO, Irene (Org.). Educação da cultura visual: conceitos e contextos. Santa Maria: Ed. da UFSM, 2011. p. 31-49.

KASTRUP, Virgínia. Aprendizagem, arte e invenção. Revista Psicologia em Estudo, Maringá, UEM, v. 6, n. 1, jan./jun. 2001, p. 17-27.

Políticas cognitivas na formação do professor e o problema do devir-mestre. Educação e Sociedade, São Paulo, v.26, n.93, set./dez. 2005 , p. 1-13

MARTINS, Alice Fátima. Da educação artística à educação para a cultura visual: revendo percursos, refazendo pontos, puxando alguns fios dessa meada... In: MARTINS, Raimundo; TOURINHO, Irene (Org.). Educação da cultura visual: narrativas de ensino e pesquisa. Santa Maria: Ed. da UFSM, 2009. p. 101-117.

MARTINS, Raimundo. A cultura visual e a construção social da arte, da imagem e das práticas do ver. In: OLIVEIRA, Marilda Oliveira de (Org.). Arte, educação e cultura. Santa Maria: Ed. da UFSM, 2007. p. 19-40.

Implicações da ideia de crise para a compreensão da experiência visual. In: ENCONTRO NACIONAL DA ANPAP, 18., Anais... 2009. Salvador: ANPAP, EDUFBA, 2009.

MASSCHELEIN, Jan. E-ducando o olhar: a necessidade de uma pedagogia pobre. Educação e Realidade, Porto Alegre, UFRGS, jan./jun. 2008, v. 33, n. 1, p. 35-48.

MEYER, Dagmar Estermann; PARAÍSO, Marlucy Alves (Org.). Metodologias de pesquisas pós-críticas em educação. Belo Horizonte: Mazza, 2012

OLIVEIRA, Marilda Oliveira de. A formação inicial do professor de artes visuais: o caso da UFSM. In: CONGRESSO
DA FEDERAÇÃO DE ARTE EDUCADORES DO BRASIL, 17., 2008. Anais... Florianópolis: CONFAEB, Ed. da UDESC. p. $1-15$.

O papel da cultura visual na formação inicial em Artes Visuais. In: MARTINS, Raimundo; TOURINHO, Irene (Org.). Educação da cultura visual: narrativas de ensino e pesquisa. Santa Maria: Ed. da UFSM, 2009. p. 213-224.

Por uma abordagem narrativa e autobiográfica: os diários de aula como foco de investigação. In: MARTINS, Raimundo; TOURINHO, Irene (Org.). Educação da cultura visual: conceitos e contextos. Santa Maria: Ed. da UFSM, 2011. p. 175-190.

ZABALA, Antoni. A prática educativa: como ensinar. Porto Alegre: Artmed, 1998.

\section{NOTAS}

1 Entendemos a ação de desterritorializar como o deslocamento, a saída do território a partir do conceito elaborado por Deleuze (1988-1989): “[...] não há território sem um vetor de saída do território e não há saída do território, ou seja, desterritorialização, sem, ao mesmo tempo, um esforço para se reterritorializar em outra parte" (p. 4).

2 Conceituamos "processo de subjetivação" a partir de Guattari (1992) como uma espécie de cartografia que cada indivíduo, cada grupo social elabora com demarcações cognitivas, mas também míticas, sintomatológicas, a partir da qual nos posicionamos em relação aos nossos afetos, nossas angústias e tentamos gerir inibições e pulsões.

3 Quando fazemos referência a um posicionamento pós-estruturalista, o pensamos como um modo de pensamento, como uma forma de escrita e de vida. Sendo o pós-estruturalismo um termo abrangente que foi cunhado para nomear uma série de análises e teorias que ampliam e, ao mesmo tempo, modificam certos pressupostos e procedimentos da análise estruturalista, tais como a leitura e a estrutura da imagem, bem como a ideia de representação e de mensagem. Para a teorização pós-estruturalista, o processo de significação é incerto, indeterminado e instável.

4 As discussões iniciais do que compreendemos hoje como "campo da cultura visual" nasceu da teoria crítica como forma de questionar conceitos e abordagens, porém já alinhadas às concepções pós-críticas. Não havendo aqui nenhuma incongruência, pois a teoria pós-crítica questiona os conceitos centrais da teoria crítica, não como opositora, mas como forma de diálogo e de interlocução.

5 De acordo com Kastrup (2005, p. 1277), "trata-se de dotar a aprendizagem da potência de invenção e de novidade".

6 Fragmento da entrevista realizada em 2010 com a professora em formação inicial Tamiris Vaz.

7 Fragmento da entrevista realizada em 2010 com a professora em formação inicial Sara Huppes.

8 Fragmento da entrevista realizada em 2010 com a professora em formação inicial Tamiris Vaz.

9 Conceito construído a partir da definição realizada pelo Itaú Cultural.

${ }^{10}$ Fragmento da fala de um dos educandos entrevistados, referindo-se à produção das camisetas, Fig. 4.

${ }^{11}$ Fragmento da fala de um dos educandos entrevistados.

${ }^{12}$ Fragmento da fala de um dos educandos entrevistados.

${ }^{13}$ Fragmento da entrevista realizada em 2010 com a professora em formação inicial Sara Huppes.

${ }^{14}$ Este subtítulo faz referência ao que diz Masschelein (2008, p. 44) sobre o caminhar enquanto uma atividade que não precisa de uma orientação e destino para dar-lhe um significado, um ponto de chegada, mas que estejamos atentos durante este caminho: "Caminhar por essa linha sem um programa, sem um fim, mas com um peso, uma carga: o que há lá para se ver e ouvir?"

15 Entendendo esta provisionalidade como uma constatação e uma possibilidade de construir e explorar a compreensão sobre como nos relacionamos com e a partir das imagens, já que este campo não tem os limites precisos de uma disciplina nem estabelece um território no qual seus fundamentos epistemológicos, políticos, metodológicos e pedagógicos estejam unificados (HERNÁNDEZ, 2011).

Artigo recebido em janeiro 2012.

Aprovado em dezembro 2013 